\title{
Evidence-based oral antiplatelet therapy among hospitalized Chinese patients with acute myocardial infarction: results from the Chinese acute myocardial infarction registry
}

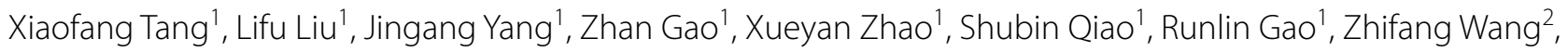
Jinqing Yuan ${ }^{1 *}$ and Yuejin Yang ${ }^{1 *}$

\begin{abstract}
Background: Oral antiplatelet therapy is the cornerstone of treatment for acute myocardial infaction (AMI). However, detailed usage data on oral antiplatelet therapy are lacking.

Methods: Using data from a nationally representative sample of patients with AMI, the detailed usage of oral antiplatelet therapy was analyzed in 40,202 consecutive eligible patients.

Results: The proportions of patients with AMI taking loading doses of aspirin and P2Y12 inhibitors were relatively low (62.2\% and $63.6 \%$, respectively), whereas approximately $90 \%$ of patients received maintenance doses of aspirin, P2Y12 inhibitors, and dual antiplatelet therapy. The proportions of patients taking loading doses of aspirin and P2Y12 inhibitors gradually decreased with age. Male sex, an educational level of at least college, an interval from onset to treatment of $<24 \mathrm{~h}$, and primary $\mathrm{PCl}$ use were associated with a higher proportion of patients taking a loading dose of antiplatelet therapy, whereas those receiving conservative treatment had a lower rate of antiplatelet use (all $P<0.05$ ). The proportion of patients taking loading doses of aspirin was highest in the western region, and that of patients taking loading doses of P2Y12 inhibitors was highest in the eastern region $(P<0.05)$. In addition, $76.7 \%$ of patients with ST-elevation MI and $91 \%$ of patients with non-ST-elevation MI received 300-mg loading dose of clopidogrel.
\end{abstract}

Conclusions: The proportion of patients with AMI receiving loading doses of aspirin and P2Y12 inhibitors during hospitalization was relatively low, and this rate was affected by many factors, such as age, sex, educational level, region of residence, and the interval from onset to treatment. The underutilization of guideline-based P2Y12 inhibitors was also problematic. Hence, quality improvement initiatives are needed to enhance adherence to guidelines to improve consistent use of oral antiplatelet therapy.

Trial registration The Chinese Acute Myocardial Infarction Registry; Trial registration number: ChiCTR-

ONC-12002636; Registered 31 October 2012; http://www.chictr.org.cn/showproj.aspx?.proj=6916

Keywords: Oral antiplatelet therapy, Acute myocardial infarction, Aspirin, P2Y12 inhibitors

*Correspondence: dr_jinqingyuan@sina.com; yangyjfw@126.com 1 Department of Cardiology, Fuwai Hospital, National Center for Cardiovascular Diseases, Chinese Academy of Medical Science and Peking Union Medical College, No. 167 North Lishi Road, Xicheng District, Beijing 100037, China

Full list of author information is available at the end of the article

\section{Background}

Myocardial infarction (MI) remains a serious public health concern, and it has emerged as the leading cause of morbidity and mortality from cardiovascular disease around the world and in China, with hospitalization rates 
increasing significantly $[1,2]$. Despite strong evidence of the benefits of both acute and longer-term management with antiplatelet therapy in patients with acute myocardial infarction (AMI), reports from Western countries indicated that physician compliance with guideline recommendations and the sustained use of antiplatelet therapy remain suboptimal and a challenging [3-7]. However, corresponding data (Evidence-based oral antiplatelet therapy among AMI patients during hospitalization and physician compliance with guideline recommendations of oral antiplatelet therapy) from China are scarce.

To date, few studies have explored this issue in China. The rate of aspirin use among patients with acute coronary syndrome (ACS) at the time of hospital discharge exceeded 90\% between 2004 and 2006 in China according to the Clinical Pathways for Acute Coronary Syndromes in China (CPACS) study [8]. The early use of aspirin in patients with AMI increased over time in China (78.4\% in $2001,86.5 \%$ in 2006 , and $90.0 \%$ in 2011), and the early rate of clopidogrel therapy for AMI in China increased from $45.7 \%$ in 2006 to $79.8 \%$ in 2011 according to the China PEACE-Retrospective AMI Study $[9,10]$.

However, detailed data regarding oral antiplatelet therapy such as the use of the loading and maintenance doses and receipt of dual antiplatelet therapy (DAPT) among Chinese patients with AMI in recent years are extremely limited. Thus, this study investigated the detailed use of oral antiplatelet therapy among hospitalized patients with AMI in a "real-world" contemporary era and determined whether oral antiplatelet use in patients with AMI accorded with current guidelines by analyzing a consecutive national sample derived from the Chinese acute myocardial infarction (CAMI) registry.

\section{Methods}

\section{Study design}

The CAMI registry is a prospective, nationwide, multicenter observational study of patients with AMI (NCT01874691). This project was approved by the institutional review board central committee at Fuwai Hospital, National Center for Cardiovascular Diseases of China (approval No.: 2012431) and conducted out in accordance with the tenets of the Declaration of Helsinki. Written informed consent was obtained from eligible patients before registration. Patient enrollment started in 2013. The registry covered all provinces and municipalities across mainland China (excluding Hong Kong and Macau), which made it likely representative of routine real-world clinical AMI care in China.

The treatment strategies for patients with ST-elevation myocardial infarction (STEMI) included primary percutaneous coronary intervention (PCI), thrombolysis, elective PCI, and conservative treatment. Primary PCI, defined as an emergent percutaneous catheter intervention in the setting of STEMI, without previous fibrinolytic treatment,was the preferred reperfusion strategy in patients with STEMI, provided that it can be performed expeditiously (i.e., within guidelinemandated times) by an experienced team and completed regardless of whether the patient presents to a PCI-capable hospital. Thrombolysis is an important reperfusion strategy, particularly in settings in which primary PCI cannot be offered to patients with STEMI within the recommended timeline. Elective PCI was defined as appropriate for percutaneous catheter intervention in the setting of STEMI and totally occluded arteries $>24 \mathrm{~h}$ after symptom onset in patients without signs of ischemia (regardless of whether fibrinolysis was performed). Conservative treatment was defined as treatment given to non-reperfused patients with STEMI that served as the only medications used as therapy [11, 12]. The treatment strategies for patients with non-STEMI (NSTEMI) included primary PCI, elective PCI, and conservative treatment. Primary PCI was defined as an early invasive strategy indicated in high-risk patients with NSTEMI who have refractory angina or hemodynamic or electrical instability (without serious comorbidities or contraindications to such procedures). Elective PCI was defined as a delayed invasive strategy for initially stabilized high-risk patients with UA/NSTEMI and those not at high risk. Conservative treatment was defined as treatment given to non-reperfused patients with NSTEMI that was the only medications used for treatment [13]. Clinical data, treatments, and outcomes were collected by local investigators and captured electronically using a fixed table, including a standardized set of variables and definitions, under rigorous data quality control. Complete details of the rationale and methodology of the CAMI registry study have been described elsewhere [14].

\section{Data collection}

In the CAMI registry, eligible patients must be admitted within 7 days of acute ischemic symptoms with a primary clinical diagnosis of AMI, including STEMI or NSTEMI. The inclusion criteria must meet the guidelines of the third Universal Definition for Myocardial Infarction (2012). Types 1, 2, 3, 4b, and 4c are included, and types 4a and 5 are not eligible for the registry. From January 2013 to January 2016, 41,375 patients were enrolled. In the present study, 1063 patients with an uncertain AMI status and 110 patients with missing data were excluded sequentially. Finally, 40,202 eligible patients with AMI were included in the present study (Fig. 1). 


\section{Statistical analyses}

Patients' baseline characteristics, medical history, treatments, and complications were evaluated. Continuous variables were presented as the mean \pm standard deviation and compared using analysis of variance. Categorical variables were presented as counts and percentages and compared with the chi-squared test or Fisher's exact test. Non-normally distributed variables were presented as the median and interquartile range and compared using Wilcoxon's rank sum test. For all analyses, two-tailed $P<0.05$ was considered statistically significant, and all analyses were performed using SAS version 9.4 (SAS Institute Inc., Cary, NC, USA).

\section{Results}

A total of 40,202 patients diagnosed with AMI were consecutively enrolled in the CAMI registry from January 2013 to January 2016. Of these, 30,179 patients had STEMI, and 10,023 patients had NSTEMI. The baseline patient characteristics are presented in Table 1. Compared to the STEMI population, the NSTEMI population had higher a proportion of patients aged $>65$ years; a higher rate of female sex; higher rates of previous MI, previous PCI, and previous coronary artery bypass surgery; and higher rates of comorbidities such as hypertension, hyperlipidemia, diabetes mellitus, peripheral arterial disease, heart failure, and stroke (all $P<0.001$ ). The NSTEMI group also had lower rates of current smokers, onset-to-visit time $<24 \mathrm{~h}$, and receipt of primary PCI (all $P<0.001$ ).

The proportions of patients taking loading doses of aspirin and P2Y12 receptor inhibitors were both higher in the STEMI group than in the NSTEMI group (both
$P<0.001)$. Conversely, the proportions of patients taking maintenance doses of aspirin and DAPT did not differ between the groups (Table 2).

\section{Detailed oral antiplatelet therapy}

The proportions of patients taking loading doses of aspirin and P2Y12 receptor inhibitors gradually decreased with age (both $P<0.05$ ), especially among patients aged $>75$ years (STEMI group: $58.9 \%$ and $59.8 \%$, respectively; NSTEMI group: $40.1 \%$ and $43.9 \%$, respectively). In the STEMI group, the proportions of patients taking maintenance doses of aspirin and DAPT were higher in patients age between 55 and $65(94.1 \%$ and $90.5 \%$, respectively) than in those $>75$ years old $(91.0 \%$ and $88.8 \%$; respectively, both $P$ ); whereas the proportions of patients taking maintenance doses of $\mathrm{P} 2 \mathrm{Y} 12$ receptor inhibitors did not differ between the age groups $(94.1 \%$ vs. $91.0 \%$; $P=0.582$ ). Among the NSTEMI group, the proportions of patients taking maintenance doses of aspirin, P2Y12 receptor inhibitors, and DAPT were higher in patients aged $55-65$ than in those aged $>75$ years $(94.9 \%$ vs. $89.7 \%, P<0.001 ; 93.0 \%$ vs. $89.8 \%, P=0.001$; and $92.6 \%$ vs. $86.3 \%$; $P<0.001$; respectively, Fig. 2 ).

The proportions of all enrolled patients of taking loading doses of aspirin and P2Y12 receptor inhibitors were both higher in men than in women $(P<0.05)$. In the STEMI group, the proportions of patients taking maintenance doses of aspirin and DAPT were both higher in men than in women $(P<0.05)$, but the rate of maintenance P2Y12 receptor inhibitor treatment did not differ between the sexes. In the NSTEMI group, the proportions of patients taking maintenance doses of aspirin,

\section{1,375 consecutive patients enrolled in CAMI registry from January 2013 up to January 2016}

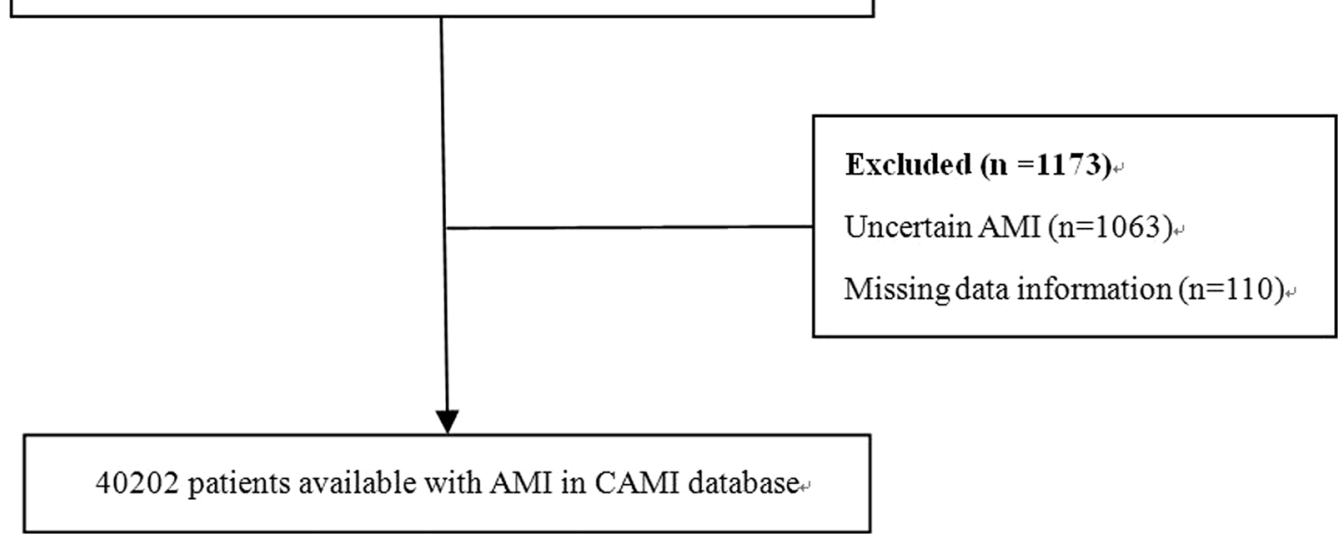

Fig. 1 Flow chart for the study population 
Table 1 Baseline characteristics of the study participants

\begin{tabular}{|c|c|c|c|c|}
\hline & $\begin{array}{l}\text { Overall population (\%/ } \\
\text { Mean } \pm \text { SD) }\end{array}$ & STEMI (\%/Mean \pm SD) & NSTEMI (\%/Mean \pm SD) & $\begin{array}{l}P \\
\text { value }\end{array}$ \\
\hline & $\mathrm{N}=40,202$ & $N=30,179$ & $\mathrm{~N}=10,023$ & \\
\hline \multicolumn{5}{|l|}{ Demographics } \\
\hline Age (years) & & & & $<0.001$ \\
\hline$<55$ & $11,786(29.32 \%)$ & 9475 (31.4\%) & $2311(23.06 \%)$ & \\
\hline $55-65$ & $11,116(27.65 \%)$ & $8562(28.37 \%)$ & $2554(25.48 \%)$ & \\
\hline $65-75$ & $10,005(24.89 \%)$ & $7218(23.92 \%)$ & $2787(27.81 \%)$ & \\
\hline$>=75$ & 7295 (18.15\%) & $4924(16.32 \%)$ & $2371(23.66 \%)$ & \\
\hline Sex & & & & $<0.001$ \\
\hline Male & $29,815(74.16 \%)$ & $22,963(76.09 \%)$ & $6852(68.36 \%)$ & \\
\hline Female & $10,387(25.84 \%)$ & $7216(23.91 \%)$ & $3171(31.64 \%)$ & \\
\hline Access $(n, \%)$ & & & & $<0.001$ \\
\hline Emergency & 4107 (10.52\%) & $3287(11.24 \%)$ & $820(8.37 \%)$ & \\
\hline External referral & $22,944(58.77 \%)$ & $16,520(56.49 \%)$ & $6424(65.56 \%)$ & \\
\hline Family members or others Referral & 9852 (25.24\%) & 8098 (27.69\%) & $1754(17.9 \%)$ & \\
\hline Hospital ward & $444(1.14 \%)$ & $249(0.85 \%)$ & $195(1.99 \%)$ & \\
\hline Self-referral & $1694(4.34 \%)$ & $1088(3.72 \%)$ & $606(6.18 \%)$ & \\
\hline Time from onset to treatment & & & & $<0.001$ \\
\hline$<24$ & $28,664(71.3 \%)$ & $22,427(74.31 \%)$ & $6237(62.23 \%)$ & \\
\hline$>24 h$ & $7873(19.58 \%)$ & 4918 (16.3\%) & $2955(29.48 \%)$ & \\
\hline Uncertain & $3665(9.12 \%)$ & $2834(9.39 \%)$ & $831(8.29 \%)$ & \\
\hline Educational level (\%) & & & & 0.0019 \\
\hline College or above & $3097(7.7 \%)$ & $2396(7.94 \%)$ & 701 (6.99\%) & \\
\hline Below junior college & $37,105(92.3 \%)$ & $27,783(92.06 \%)$ & $9322(93.01 \%)$ & \\
\hline Regions & & & & $<0.001$ \\
\hline Eastern & $15,929(39.62 \%)$ & $11,577(38.36 \%)$ & $4352(43.42 \%)$ & \\
\hline Central & $18,101(45.03 \%)$ & $13,961(46.26 \%)$ & $4140(41.3 \%)$ & \\
\hline western & $6172(15.35 \%)$ & $4641(15.38 \%)$ & $1531(15.27 \%)$ & \\
\hline \multicolumn{5}{|l|}{ Medical history (n, \%) } \\
\hline Previous Ml & $2894(7.2 \%)$ & $1751(5.8 \%)$ & $1143(11.4 \%)$ & $<0.001$ \\
\hline Previous $\mathrm{PCl}$ & $750(1.87 \%)$ & $496(1.64 \%)$ & $254(2.53 \%)$ & $<0.001$ \\
\hline Previous CABG & $144(0.36 \%)$ & $60(0.2 \%)$ & $84(0.84 \%)$ & $<0.001$ \\
\hline Previous heart failure & $938(2.33 \%)$ & $379(1.26 \%)$ & $559(5.58 \%)$ & $<0.001$ \\
\hline Previous stroke & $3524(8.77 \%)$ & 2525 (8.37\%) & $999(9.97 \%)$ & $<0.001$ \\
\hline Previous peripheral arterial disease & $271(0.67 \%)$ & $157(0.52 \%)$ & $114(1.14 \%)$ & $<0.001$ \\
\hline Bleeding history & $459(1.14 \%)$ & $330(1.09 \%)$ & $129(1.29 \%)$ & 0.1188 \\
\hline \multicolumn{5}{|l|}{ Cardiovascular risk factors ( $\mathrm{n}, \%)$} \\
\hline Diabetes mellitus & $7504(18.67 \%)$ & $5166(17.12 \%)$ & $2338(23.33 \%)$ & $<0.001$ \\
\hline Hypertension & $19,661(48.91 \%)$ & $13,958(46.25 \%)$ & $5703(56.9 \%)$ & $<0.001$ \\
\hline Hyperlipidemia & 2808 (6.98\%) & $1991(6.6 \%)$ & $817(8.15 \%)$ & $<0.001$ \\
\hline Family history of premature CAD & $1237(3.08 \%)$ & $952(3.15 \%)$ & $285(2.84 \%)$ & 0.1151 \\
\hline Current smoker & $18,661(46.42 \%)$ & $13,412(44.44 \%)$ & $5249(52.37 \%)$ & $<0.001$ \\
\hline \multicolumn{5}{|l|}{ Treatment strategy (n, \%) } \\
\hline Primary PCl & $14,186(35.29 \%)$ & $12,998(43.07 \%)$ & $1188(11.85 \%)$ & $<0.001$ \\
\hline Elective PCl & $9260(23.03 \%)$ & $6389(21.17 \%)$ & $2871(28.64 \%)$ & $<0.001$ \\
\hline Conservation & $5149(12.81 \%)$ & $3580(11.86 \%)$ & $1569(15.65 \%)$ & $<0.001$ \\
\hline
\end{tabular}

STEMI, ST-elevation myocardial infarction; NSTEMI, non-ST-elevation myocardial infarction; SD, standard deviation; MI, myocardial infarction; $\mathrm{PCl}$, percutaneous coronary intervention; $C A B G$, coronary artery bypass graft; $C A D$, coronary artery disease 
Table 2 Detailed antiplatelet treatment in AMI patients

\begin{tabular}{lclll}
\hline & $\begin{array}{l}\text { Overall population (\%/ } \\
\text { Mean } \pm \text { SD) } \\
\mathbf{N}=\mathbf{4 0 , 2 0 2}\end{array}$ & STEMI (\%/Mean \pm SD) & NSTEMI (\%/Mean \pm SD) & P value \\
\hline Antiplatelet treatment strategy $(\mathrm{n}, \%)$ & & $\mathbf{N 0 , 1 7 9}$ & \\
Aspirin loading & $25,011(62.2 \%)$ & $19,901(65.9 \%)$ & $5110(51.0 \%)$ \\
P2Y12 loading & $25,557(63.6 \%)$ & $19,993(66.2 \%)$ & $5564(55.5 \%)$ & $<0.001$ \\
Aspirin maintenance & $37,414(93.1 \%)$ & $28,087(93.1 \%)$ & $9327(93.1 \%)$ & $<0.001$ \\
P2Y12 maintenance & $36,405(90.6 \%)$ & $27,249(90.3 \%)$ & $9156(91.3 \%)$ & 0.967 \\
DAPT & $36,154(89.9 \%)$ & $27,134(89.9 \%)$ & $9020(90.0 \%)$ & 0.002 \\
\hline
\end{tabular}

STEMI, ST-elevation myocardial infarction; NSTEMI, non-ST-elevation myocardial infarction; DAPT, dual antiplatelet treatment

P2Y12 receptor inhibitors, and DAPT were all higher in men than in women (all $P<0.05$, Fig. 3).

The proportions of patients taking loading and maintenance doses of aspirin, P2Y12 receptor inhibitors, and DAPT also differed according to the treatment strategies employed in patients with AMI $(P<0.05$, Fig. 4$)$. In STEMI group, the proportions of patients taking loading doses of aspirin and P2Y12 receptor inhibitors were relatively high, among those who received primary PCI $(78.8 \%$ and $79.0 \%$, respectively) and thrombolytic therapy (83\% and $79.3 \%$, respectively); conversely, the proportions were relatively low among patients who received elective PCI therapy $(60.9 \%$ and $64.8 \%$, respectively) and conservative therapy (56.9\% and $56.5 \%$, respectively). Meanwhile, the proportions of patients taking maintenance doses of aspirin and P2Y12 receptor inhibitors and DAPT were highest among those receiving elective PCI therapy $(98.6 \%, 97.8 \%$ and

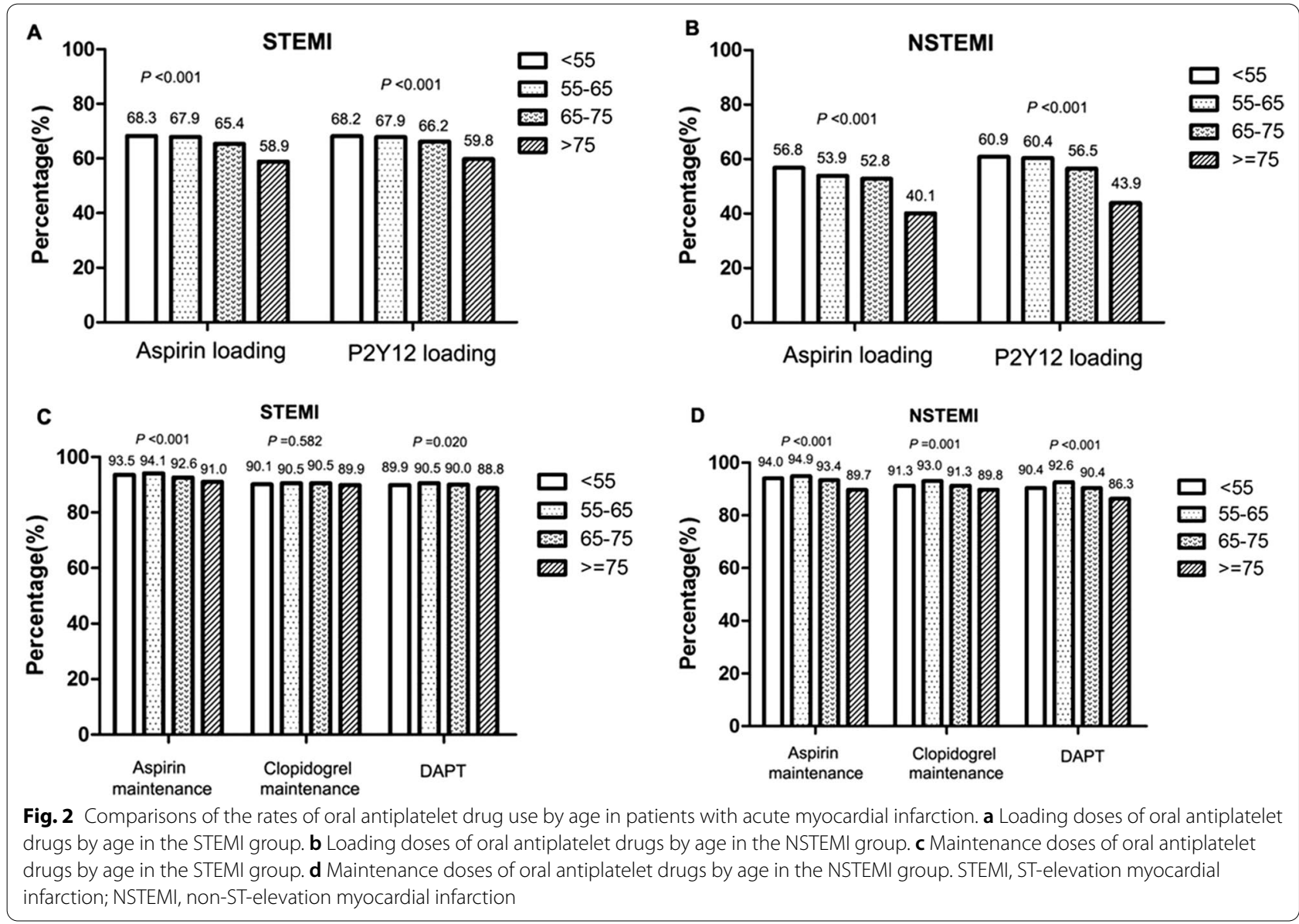



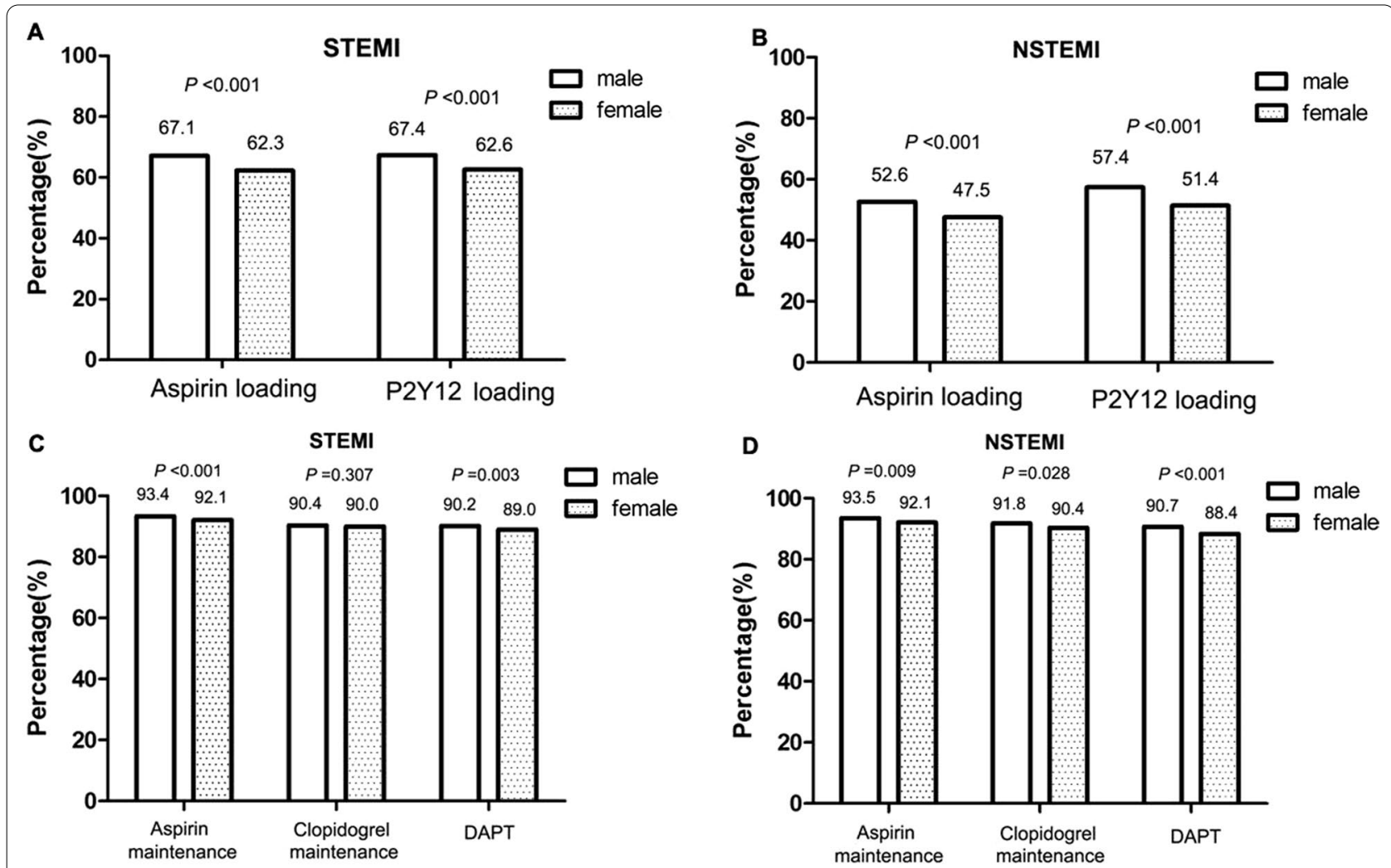

Fig. 3 Comparisons of the rates of oral antiplatelet drug use by gender in patients with acute myocardial infarction. a Loading doses of oral antiplatelet drugs by gender in the STEMI group; b loading doses of oral antiplatelet drugs by gender in the NSTEMI group. c Maintenance doses of oral antiplatelet drugs by gender in the STEMI group. d Maintenance doses of oral antiplatelet drugs by gender in the NSTEMI group. STEMI, ST-elevation myocardial infarction; NSTEMI, non- ST-elevation myocardial infarction

97.5\%, respectively) and lowest among those receiving conservative therapy $(93.2 \%, 91.7 \%$ and $90.4 \%$, respectively). In the NSTEMI group, the proportions of patients taking loading doses of aspirin and P2Y12 receptor inhibitors were highest, among those receiving primary PCI (66.9\% and $70.3 \%$, respectively) and lowest among those receiving conservative therapy (50.1\% and $52.7 \%$, respectively). In addition, the proportions of patients taking maintenance doses of aspirin, P2Y12 receptor inhibitors, and DAPT were highest among those receiving elective PCI therapy $(98.6 \%, 98.4 \%$ and $98.1 \%$, respectively).

The proportions of patients taking loading doses of aspirin and P2Y12 receptor inhibitors were higher among those with at least a college education than in those with less education $(P<0.05$, Fig. 5). In the STEMI group, the proportions of patients taking maintenance doses of aspirin, P2Y12 receptor inhibitors, and DAPT were all higher among those with at least a college education (all $P<0.05$ ). Conversely, in the NSTEMI group, the proportion of patients taking maintenance doses of aspirin was higher among those with at least a college education
$(P<0.05)$, whereas no difference in the use of maintenance doses of P2Y12 receptor inhibitors and DAPT were observed according to the educational level.

The proportions of patients taking loading doses of aspirin and P2Y12 receptor inhibitors were higher among those with an interval from onset to treatment of $<24 \mathrm{~h}$ than in those with a longer interval $(P<0.05)$. In both the STEMI and NSTEMI groups, the proportions of patients taking maintenance doses of aspirin and DAPT did not differ according to the interval from onset to treatment (Fig. 6).

The proportions of patients taking loading and maintenance doses of aspirin, P2Y12 receptor inhibitors, and DAPT were differed according to the region of residence $(P<0.05$, Fig. 7$)$. Among the entire cohort, the proportion of patients taking loading doses of aspirin was highest in the western region, and lowest in the middle region, whereas the proportion of patients taking loading doses of P2Y12 receptor inhibitors was highest in the eastern region and lowest in the middle region $(P<0.05)$. Meanwhile, the proportion of patients taking maintenance doses of P2Y12 receptor inhibitors and DAPT was 


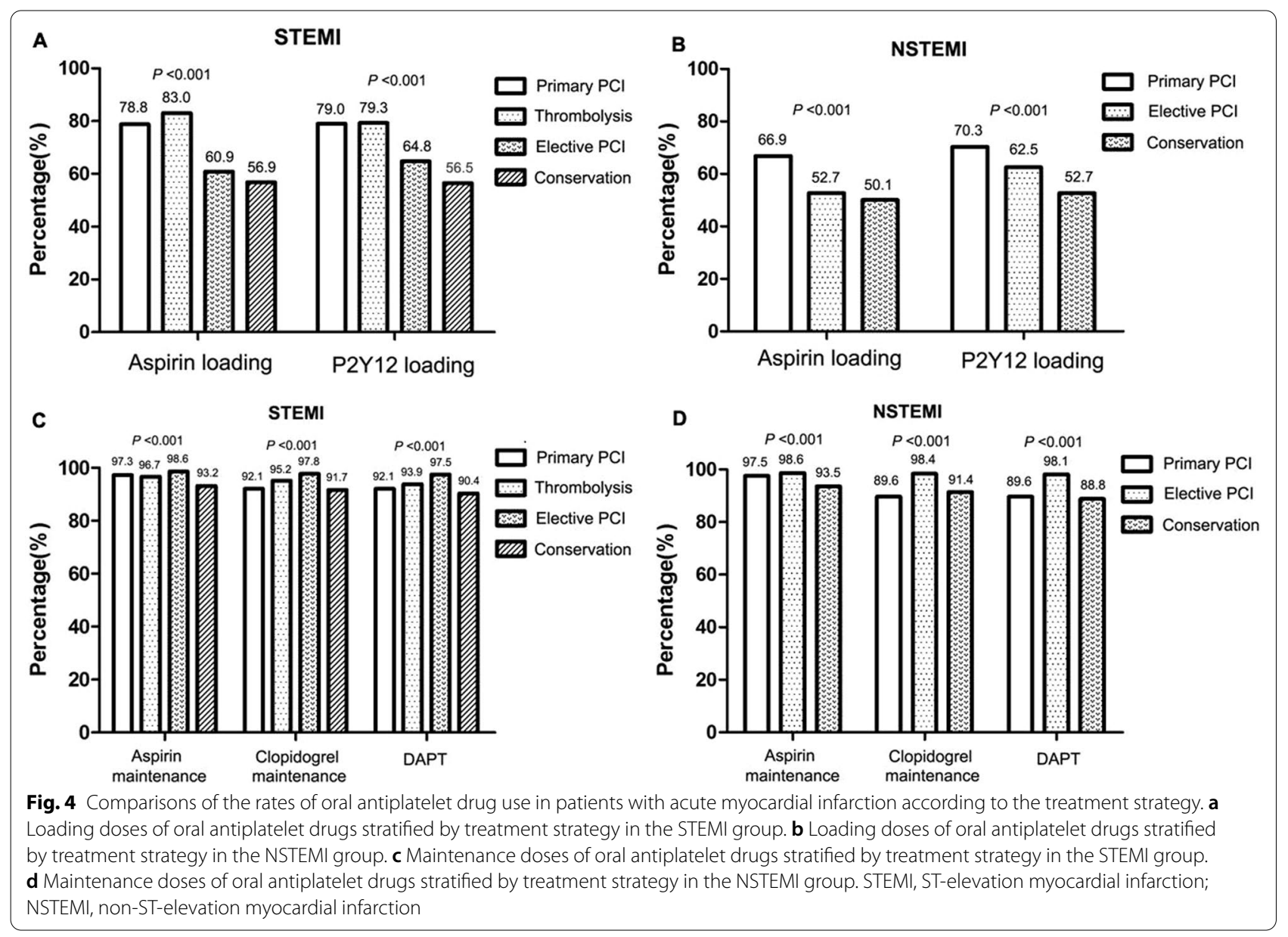

highest in the eastern region and lowest in the western region $(P<0.05)$.

\section{Utilization of $\mathrm{P} 2 \mathrm{Y} 12$ receptor inhibitors}

In the STEMI group, $76.7 \%$ of patients used a clopidogrel loading dose of $300 \mathrm{mg}, 21.4 \%$ used a clopidogrel loading dose of $600 \mathrm{mg}$, and $1.9 \%$ used a ticagrelor loading dose of $180 \mathrm{mg}$. Moreover, $89.6 \%$ of patients used a clopidogrel maintenance dose of $75 \mathrm{mg} /$ day, $8.3 \%$ used a clopidogrel maintenance dose of $100-150 \mathrm{mg} /$ day, $0.38 \%$ used a clopidogrel maintenance dose of $25-50 \mathrm{mg} /$ day, and $1.72 \%$ used a ticagrelor maintenance dose of $90-180 \mathrm{mg} /$ day (Additional file 1: Fig. 1A and 1B).

In the NSTEMI cohort, $91 \%$ of patients used a clopidogrel loading dose of $300 \mathrm{mg}, 8 \%$ used a clopidogrel loading dose of $600 \mathrm{mg}$, and $1 \%$ used a ticagrelor loading dose of $180 \mathrm{mg}$. Moreover, $92.7 \%$ of patients used a clopidogrel maintenance dose of $75 \mathrm{mg} /$ day, $5.6 \%$ used a clopidogrel maintenance dose of $100-150 \mathrm{mg} /$ day, $0.93 \%$ used a clopidogrel maintenance dose of $25-50 \mathrm{mg} /$ day, and $0.77 \%$ used a ticagrelor maintenance dose of $90-180 \mathrm{mg} /$ day (Additional file 2: Fig. 2A and 2B).

\section{Discussion}

The major findings of this study were as follows: (1) The use of oral antiplatelet drugs during hospitalization had increased in Chinese patients with AMI in recent years. (2) In this study of a nationally representative sample of hospitalized patients in China, the usage of oral antiplatelet therapy by patients with AMI was affected by many factors, such as age, sex, educational level, regions, time since onset and treatment strategies. (3) Among patients with AMI, the most commonloading and maintenance doses of clopidogrel were 300 and $75 \mathrm{mg}$, respectively, from 2013 to 2016.

The epidemiological characteristics and real-world oral antiplatelet treatment of AMI have not been well studied in Asian countries despite its importance in public health. The CPACS registry found that 93\% of all patients with ACS were prescribed aspirin, but only $44.6 \%$ of patients were prescribed clopidogrel at hospital discharge between September 2004 and May 2006 [8]. In the China-PACE study, the early use of aspirin in patients with AMI in China increased over time (78.4\% in $2001,86.5 \%$ in 2006 , and $90.0 \%$ in 2011 ), and 

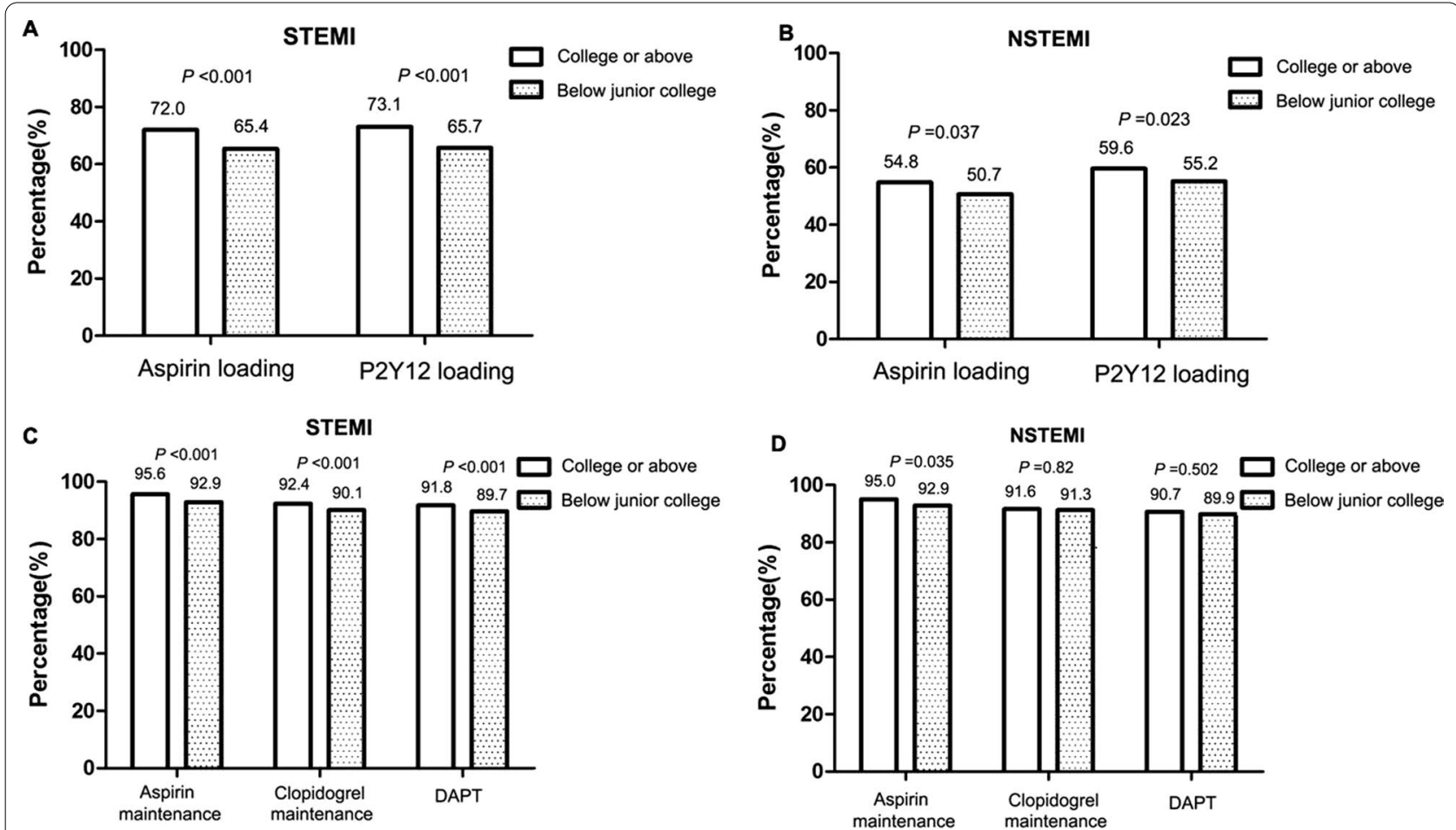

Fig. 5 Comparisons of the rates of oral antiplatelet drug use by educational levels in patients with acute myocardial infarction. a Loading doses of oral antiplatelet drugs by educational level in the STEMI group. $\mathbf{b}$ Loading doses of oral antiplatelet drugs by educational level in the NSTEMI group. c Maintenance doses of oral antiplatelet drugs by educational level in the STEMI group. $\mathbf{d}$ Maintenance doses of oral antiplatelet drugs by educational level in the NSTEMI group. STEMI, ST-elevation myocardial infarction; NSTEMI, non-ST-elevation myocardial infarction

the early rate of clopidogrel therapy in Chinese patients with AMI significantly increased from $45.7 \%$ in 2006 to $79.8 \%$ in $2011(P<0.001)[9,10]$. In the present descriptive study, the proportions of patients with AMI who received maintenance doses of aspirin and clopidogrel both exceeded $90 \%$, far exceeding the findings in prior studies $[8-10,15]$. Meanwhile, almost $90 \%$ of patients with AMI were taking DAPT in our study, compared to rates in Taiwan of $65 \%$ in 2004 and $83.9 \%$ in 2008 [15].

In the present study, the utilization ratio of oral antiplatelet therapy in Chinese patients with AMI during hospitalization was affected by many factors, such as age, sex, educational level, region of residence, treatment strategy, and time from onset to treatment. As we know, longer time from onset to treatment may influence the selection of treatment strategys, and patients with lower educational levels may have worse economic conditions, which can also influence the choice of treatment. In our study, patients with lower educational level and a longer time from onset to treatment were less likely to receive oral antiplatelet therapy, especially loading doses of antiplatelet drugs. Meanwhile, patients who underwent primary PCI were more likely to receiving loading doses of oral antiplatelet therapy, patients who underwent elective PCI were more likely to receiving maintenance doses of oral antiplatelet therapy and DAPT, and patients who received conservative treatment were less likely to receiving oral antiplatelet therapy. Meanwhile, older and female patients were also less likely to receive oral antiplatelet therapy, especially loading doses of antiplatelet drugs, in our study. Economic development is imbalanced among the regions of China. In our study, the utilization rate of both loading and maintenance doses of P2Y12 receptor inhibitors was higher in the eastern region than that in other regions. The reason for this finding may be the relatively high price of P2Y12 receptor inhibitors based on the better economic condition in the eastern region.

In the clinic, individualized treatment with oral antiplatelet drugs is necessary to balance the risks of bleeding and ischemia within the context of the available evidence. Clinical factors increasing the risk of bleeding (e.g., age $>75$ years old, female sex, prior stroke, body 

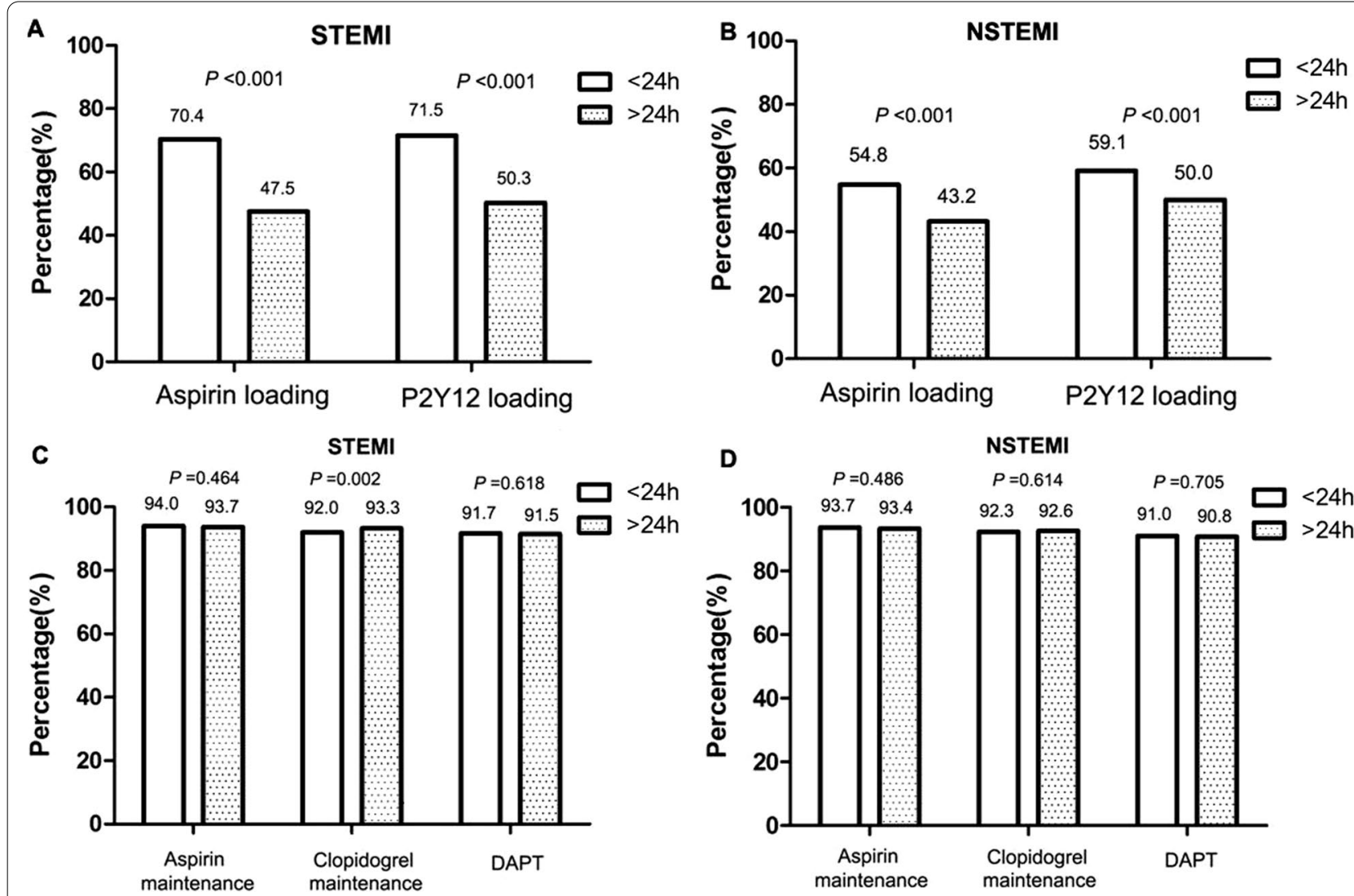

Fig. 6 Comparisons of the rates of oral antiplatelet drug use by time from onset to treatment in patients with acute myocardial infarction. a Loading doses of oral antiplatelet drugs by the time from onset to treatment in the STEMI group. $\mathbf{b}$ Loading doses of oral antiplatelet drugs by the time from onset to treatment in the NSTEMI group. c Maintenance doses of oral antiplatelet drugs by the time from onset to treatment in the STEMI group. $\mathbf{d}$ Maintenance doses of oral antiplatelet drugs by the time from onset to treatment in the NSTEMI group. STEMI, ST-elevation myocardial infarction; NSTEMI, non-ST-elevation myocardial infarction

weight $<60 \mathrm{~kg}$, renal dysfunction) and ischemia (e.g., diabetes mellitus, peripheral artery disease, prior cardiovascular event, prior coronary revascularization, left main stenting, bifurcation stenting) should be considered in the recommendation of oral antiplatelet therapy $[7,15-$ 23]. In clinical practice, carefully selected patients may derive the greatest benefit from more intense antithrombotic therapy after AMI [24, 25].

In 2010, Chinese guidelines for patients with STEMI recommended an oral aspirin loading dose of $300 \mathrm{mg}$, followed by a maintenance dose of $100 \mathrm{mg} /$ day, and an oral clopidogrel loading dose of $300 \mathrm{mg}$, followed by a maintenance dose of $75 \mathrm{mg} /$ day [26]. The 2012 European Society of Cardiology (ESC) and 2013 American College of Cardiology (ACC)/American Heart Association (AHA) guidelines for STEMI recommended an oral clopidogrel loading dose of $600 \mathrm{mg}$ orally, followed by a maintenance dose of $75 \mathrm{mg} /$ day, whereas the recommendation for ticagrelor was an oral loading dose of $180 \mathrm{mg}$, followed by a maintenance dose of $90 \mathrm{mg}$ b.i.d $[11,12]$.
The 2012 ACCF/AHA guideline for UA/NSTEMI also mentioned new P2Y12 inhibitors, including ticagrel [13]. It was not until 2015 that the ticagrelor was first recommended in the updated Chinese STEMI guidelines, which recommended an oral clopidogrel loading dose of $600 \mathrm{mg}$, followed by a maintenance dose of $75 \mathrm{mg} /$ day and an oral ticagrelor loading dose of $180 \mathrm{mg}$, followed by a maintenance dose of $90 \mathrm{mg}$ b.i.d [27].

The patients in our study were enrolled between 2013 and 2016. Among the patients with AMI, the most common loading and maintenance doses of clopidogrel were 300 and $75 \mathrm{mg}$, respectively. Because this study was descriptive in nature, we could not identify the reasons for the usage habits of P2Y12 receptor inhibitors. In the ESC 2012 or ACC 2013 guidelines, the loading dose of clopidogrel was initially recommended as $600 \mathrm{mg}$; however, the Chinese guidelines only updated the high loading dose of clopidogrel in 2015, which may partly explain the use of a low clopidogrel loading dose of $300 \mathrm{mg}$. At the same time, it was only in 2015 that the Chinese 

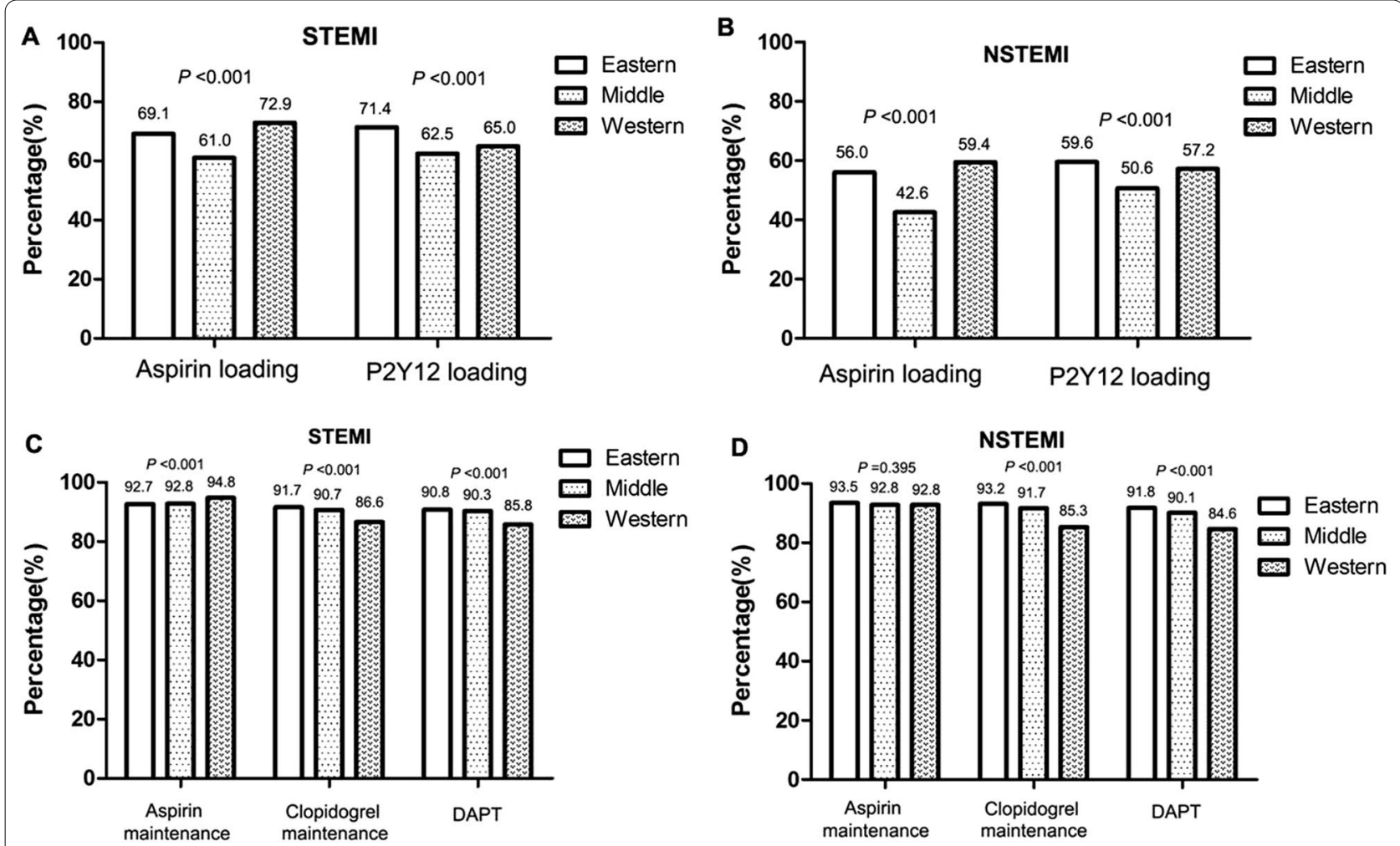

Fig. 7 Comparisons of the rates of oral antiplatelet drug use by region of residence in patients with acute myocardial infarction. a Loading doses of oral antiplatelet drugs by region of residence in the STEMI group. $\mathbf{b}$ Loading doses of oral antiplatelet drugs by region of residence in the NSTEMI group. c Maintenance doses of oral antiplatelet drugs by region of residence in the STEMI group. d Maintenance doses of oral antiplatelet drugs by region of residence in the NSTEMI group. STEMI, ST-elevation myocardial infarction; NSTEMI, non-ST-elevation myocardial infarction

guidelines recommended the use of ticagrelor, which may explain the low use of this drug. In addition, the common reason for the low use of high-dose loading clopidogrel and ticagrelor is the risk of bleeding. The ACC/AHA guidelines for STEMI and NSTEMI are widely upheld in China, and China's own guidelines are widely recognized; however, these findings suggest a significant gap between evidence and practice, which may, in large part, be attributable to a lack of familiarity with current treatment recommendations. The PROGRESS trial investigated the adherence to ticagrelor therapy in patients after ACS [28]. Adherence to antithrombotic treatment in patients with AMI is extremely important, hence, increasing the prescription rate of guideline-based medications through quality improvement programs may be necessary to enhance adherence to AMI treatment guidelines. In addition to antithrombotic drug treatment, the control of other risk factors, particularly LDL and Lp(a), which were considered to be the independent risk factors of atherosclerotic cardiovascular disease, especially in patients with AMI, is also important [29-31].

\section{Limitations}

As the first prospective national registry study of patients with AMI in China, the CAMI registry study revealed current problems in the Chinese health care system. Data were valuable, specific, and updated, and they were based on a large population base. The CAMI study has five steps to support data quality control in the registry [14]. Nevertheless, our study had several limitations. First, the CAMI study was subject to inherent limitations and potential biases, including the collection of non-randomized data, missing or incomplete information, and potential confounding by drug indications or other unmeasured covariates that must be considered in result interpretation. Second, we did not include follow-up data with oral antiplatelet drugs after hospital discharge. Future research plans to further explore how to follow guidelines to improve the usability and compliance of antiplatelet drug therapy. 


\section{Conclusions}

There was a progressive improvement in the use of oral antiplatelet treatment for patients with AMI in China, and this improvement was also affected by many factors, such as age, sex, educational levels, and treatment strategies. However, under utilization of the guidelinebased P2Y12 receptor inhibitors for AMI is a major problem in China. The guideline-based oral antiplatelet therapies in patients with AMI in China present an important clinical implication; thus, national policies and initiatives are necessary to enhance adherence to the guidelines to improve oral antiplatelet therapy.

\section{Supplementary Information}

The online version contains supplementary material available at https://doi. org/10.1186/s12872-021-02115-1.

Additional file 1: Figure 1. Rate of loading doses of $P 2 Y 12$ receptor inhibitor use among patients with acute myocardial infarction. A, loading doses in the STEMI group. B, loading doses in the NSTEMI group. STEMI, ST-elevation myocardial infarction; NSTEMI, non- ST-elevation myocardial infarction

Additional file 2: Figure 2. Rate of maintenance doses of P2Y12 receptor inhibitor use among patients with acute myocardial infarction. A, maintenance doses in the STEMI group; B, maintenance doses in the NSTEMI group. STEMI, ST-elevation myocardial infarction; NSTEMI, non- ST-elevation myocardial infarction

\section{Acknowledgements}

The authors expressed their gratitude to all investigators and coordinators who participated in the CAMI registry. Further information about the CAMI project, along with a list of participants, is available at http://www.CAMIRegist ry.org. We thank Joe Barber Jr., PhD, from LiwenBianji (Edanz) (www.liwen bianji.cn/), for editing the English text of a draft of this manuscript.

\section{Authors' contributions}

Conception and design the study and final approval of the manuscript: $Y Y$ and $J Y$; study design, data interpretation, and manuscript writing: TX; analysis and interpretation of data: LL; study design and critical revision of the manuscript for important intellectual content: YJ, GZ, ZX, QS, GR, WQ, and WZ. All authors read and approved the final manuscript.

\section{Funding}

The project was financially supported by one of the National Twelfth Five-year Science and Technology Support Projects by the Ministry of Science and Technology of China (Grant No. 2011BAl11B02).

\section{Availability of data and materials}

The dataset analyzed in the current study is not publicly available because of the lack of consent from the study participants, but it is available from the corresponding author on reasonable request for researchers who meet the criteria for access to confidential data.

\section{Declarations}

\section{Ethics approval and consent to participate}

This project was approved by the institutional review board central committee of Fuwai Hospital, National Center for Cardiovascular Diseases of China (approval No.: 2012431) and conducted in accordance with the tenets of the Declaration of Helsinki. The CAMI registry study group maintains the institutional review board-approved protocol that describes the methods used to protect the privacy of patients and maintain confidentiality of data collected. Written informed consent was obtained from eligible patients before registration. However, to avoid registration biases associated with informed consent and ensure all eligible patients being registered, investigators can register patients without providing informed consent. However, the data were anonymized, and private information was omitted.

\section{Consent for publication}

Not applicable.

\section{Competing interests}

All authors declared no competing financial interests.

\section{Author details}

${ }^{1}$ Department of Cardiology, Fuwai Hospital, National Center for Cardiovascular Diseases, Chinese Academy of Medical Science and Peking Union Medical College, No. 167 North Lishi Road, Xicheng District, Beijing 100037, China. ${ }^{2}$ Department of Cardiology, The Central Hospital of Xinxiang, Xinxiang, Henan Province, China.

Received: 7 April 2021 Accepted: 9 June 2021

Published online: 14 June 2021

\section{References}

1. Beaglehole R. Global cardiovascular disease prevention: time to get serious. Lancet. 2001;358:661-3.

2. Rodriguez F, Mahaffey KW. Management of patients with NSTE-ACS: a comparison of the recent AHA/ACC and ESC guidelines. J Am Coll Cardiol. 2016;68:313-21.

3. Sud A, Kline-Rogers EM, Eagle KA, Fang J, Armstrong DF, Rangarajan K, Otten RF, Stafkey-Mailey DR, Taylor SD, Erickson SR. Adherence to medications by patients after acute coronary syndromes. Ann Pharmacother. 2005;39:1792-7.

4. Singh M, Bhatt DL, Stone GW, Rihal CS, Gersh BJ, Lennon RJ, Narula J, Fuster $V$. Antithrombotic approaches in acute coronary syndromes: optimizing benefit vs bleeding risks. Mayo Clin Proc. 2016;91:1413-47.

5. Sinnaeve PR, Desmet W, Descamps O, Gevaert S, De Backer G, Kolh P, Vrolix M, Van De Borne P, De Meester A, Claeys MJ, Beauloye C. One-year and longer dual antiplatelet therapy after an acute coronary syndrome: a Belgian position paper. Acta Cardiol. 2017;72:19-27.

6. Makam RC, Erskine N, McManus DD, Lessard D, Gore JM, Yarzebski J, Goldberg RJ. Decade-long trends (2001 to 2011) in the use of evidence-based medical therapies at the time of hospital discharge for patients surviving acute myocardial infarction. Am J Cardiol. 2016;118:1792-7.

7. Collart P, Coppieters Y, Leveque A. Trends in acute myocardial infarction treatment between 1998 and 2007 in a Belgian area (Charleroi). Eur J Prev Cardiol. 2012;19:738-45.

8. Bi Y, Gao R, Patel A, Su S, Gao W, Hu D, Huang D, Kong L, Qi W, Wu Y, Yang $Y$, Turnbull F, Investigators C. Evidence-based medication use among Chinese patients with acute coronary syndromes at the time of hospital discharge and 1 year after hospitalization: Results from the clinical pathways for acute coronary syndromes in china (CPACS) study. Am Heart J. 2009;157:509-516 e501.

9. Gao Y, Masoudi FA, Hu S, Li J, Zhang H, Li X, Desai NR, Krumholz HM, Jiang L, China PCG. Trends in early aspirin use among patients with acute myocardial infarction in China, 2001-2011: the China peace-retrospective AMl study. J Am Heart Assoc. 2014;3:1250.

10. Zhang L, Desai NR, Li J, Hu S, Wang Q, Li X, Masoudi FA, Spertus JA, Nuti SV, Wang S, Krumholz HM, Jiang L, China PCG. National quality assessment of early Clopidogrel therapy in Chinese patients with acute myocardial infarction (AMI) in 2006 and 2011: Insights from the china patientcentered evaluative assessment of cardiac events (PEACE)-retrospective AMl study. J Am Heart Assoc. 2015;4

11. Task Force on the Management of STseamiotESoC, Steg PG, James SK, Atar D, Badano LP, Blomstrom-Lundqvist C, Borger MA, Di Mario C, Dickstein K, Ducrocq G, Fernandez-Aviles F, Gershlick AH, Giannuzzi P, Halvorsen S, Huber K, Juni P, Kastrati A, Knuuti J, Lenzen MJ, Mahaffey KW, Valgimigli M, van Hof A, Widimsky P, Zahger D. Esc guidelines for the management of acute myocardial infarction in patients presenting with ST-segment elevation. Eur Heart J. 2012;33:2569-619. 
12. American College of Emergency P, Society for Cardiovascular A, Interventions, Ogara PT, Kushner FG, Ascheim DD, Casey DE Jr, Chung MK, de Lemos JA, Ettinger SM, Fang JC, Fesmire FM, Franklin BA, Granger CB, Krumholz HM, Linderbaum JA, Morrow DA, Newby LK, Ornato JP, Ou N, Radford MJ, Tamis-Holland JE, Tommaso CL, Tracy CM, Woo YJ, Zhao DX, Anderson JL, Jacobs AK, Halperin JL, Albert NM, Brindis RG, Creager MA, DeMets D, Guyton RA, Hochman JS, Kovacs RJ, Kushner FG, Ohman EM, Stevenson WG, Yancy CW. 2013 ACCF/AHA guideline for the management of ST-elevation myocardial infarction: a report of the American college of cardiology foundation/American heart association task force on practice guidelines. J Am Coll Cardiol. 2013;61:e78-140.

13. Writing Committee $M$, Jneid $H$, Anderson JL, Wright RS, Adams CD, Bridges CR, Casey DE Jr, Ettinger SM, Fesmire FM, Ganiats TG, Lincoff AM, Peterson ED, Philippides GJ, Theroux P, Wenger NK, Zidar JP, Anderson $J L$, American College of Cardiology F, American Heart Association Task Force on Practice G. 2012 ACCF/AHA focused update of the guideline for the management of patients with unstable angina/non-ST-elevation myocardial infarction (updating the 2007 guideline and replacing the 2011 focused update): a report of the American college of cardiology foundation/American heart association task force on practice guidelines. Circulation. 2012;126:875-910.

14. Xu H, Li W, Yang J, Wiviott SD, Sabatine MS, Peterson ED, Xian Y, Roe MT, Zhao W, Wang Y, Tang X, Jia X, Wu Y, Gao R, Yang Y. Group CRs. The china acute myocardial infarction (CAMI) registry: a national long-term registryresearch-education integrated platform for exploring acute myocardial infarction in china. Am Heart J. 2016;175:193-201193.

15. Lee $\mathrm{CH}$, Cheng $\mathrm{CL}$, Yang YH, Chao TH, Chen JY, Liu PY, Lin CC, Chan SH, Tsai LM, Chen JH, Lin LJ, Li YH. Trends in the incidence and management of acute myocardial infarction from 1999 to 2008: get with the guidelines performance measures in Taiwan. J Am Heart Assoc. 2014;3

16. Bagai $A$, Bhatt $D L$, Eikelboom JW, Mancini GB, Cohen EA, Vijayaraghavan $R$, Cheema AN, Udell JA, Niznick J, Tanguay JF, Verma S, Mehta SR. Individualizing duration of dual antiplatelet therapy after acute coronary syndrome or percutaneous coronary intervention. Circulation. 2016;133:2094-8.

17. Xu JJ, Gao Z, Zhang Y, Gao LJ, Chen J, Qiao SB, Gao RL, Yang YJ, Xu B, Yuan $J Q$. Dual antiplatelet therapy after coronary drug-eluting stent implantation in china: a large single center study. Catheter Cardiovasc Interv. 2018

18. Nedkoff $\sqcup$, Briffa TG, Preen DB, Sanfilippo FM, Hung J, Ridout SC, Knuiman $M$, Hobbs M. Age- and sex-specific trends in the incidence of hospitalized acute coronary syndromes in western australia. Circ Cardiovasc Qual Outcomes. 2011;4:557-64.

19. Daida H, Miyauchi K, Ogawa H, Yokoi H, Matsumoto M, Kitakaze M, Kimura T, Matsubara T, Ikari Y, Kimura K, Tsukahara K, Origasa H, Morino Y, Tsutsui H, Kobayashi M, Isshiki T, Invegators P. Management and two-year long-term clinical outcome of acute coronary syndrome in japan: prevention of atherothrombotic incidents following ischemic coronary attack (pacific) registry. Circul J. 2013;77:934-43.

20. Lin CC, Li Cl, Hsiao CY, Liu CS, Yang SY, Lee CC, Li TC. Time trend analysis of the prevalence and incidence of diagnosed type 2 diabetes among adults in taiwan from 2000 to 2007: a population-based study. BMC Public Health. 2013;13:318.

21. Ueshima H, Sekikawa A, Miura K, Turin TC, Takashima N, Kita Y, Watanabe M, Kadota A, Okuda N, Kadowaki T, Nakamura Y, Okamura T.
Cardiovascular disease and risk factors in Asia: a selected review. Circulation. 2008;1 18:2702-9.

22. Su TC, Bai CH, Chang HY, You SL, Chien KL, Chen MF, Chen HJ, Pan WH, Tseng CH, Cheng SH, Hurng BS, Hwang LC, Chen CJ. Evidence for improved control of hypertension in Taiwan: 1993-2002. J Hypertens. 2008;26:600-6.

23. Hardoon SL, Whincup PH, Lennon LT, Wannamethee SG, Capewell S, Morris RW. How much of the recent decline in the incidence of myocardial infarction in British men can be explained by changes in cardiovascular risk factors? Evidence from a prospective population-based study. Circulation. 2008;117:598-604.

24. Gragnano F, Moscarella E, Calabro P, Cesaro A, Pafundi PC, lelasi A, Patti G, Cavallari I, Antonucci E, Cirillo P, Pignatelli P, Palareti G, Pelliccia F, Gaudio C, Sasso FC, Pengo V, Gresele P, Marcucci R, Collaborators S-A. Clopidogrel versus ticagrelor in high-bleeding risk patients presenting with acute coronary syndromes: insights from the multicenter start-antiplatelet registry. Intern Emerg Med. 2021;16:379-87.

25. Cesaro A, Taglialatela V, Gragnano F, Moscarella E, Fimiani F, Conte M, Barletta V, Monda E, Limongelli G, Severino S, Cirillo P, Calabro P. Low-dose ticagrelor in patients with high ischemic risk and previous myocardial infarction: a multicenter prospective real-world observational study. J Cardiovasc Pharmacol. 2020;76:173-80.

26. <2010年急性st段抬高型心肌梗死诊断和治疗指南.Pdf>.

27. China Society of Cardiology of Chinese Medical Association EBoCJoC, China Society of Cardiology of Chinese Medical Association Editorial Board of Chinese Journal of $C$. [guideline on the diagnosis and therapy of st-segment elevation myocardial infarction]. Zhonghua xin xue guan bing za zhi. 2015;43:380-393

28. Crisci M, Gragnano F, Di Maio M, Diana V, Moscarella E, Pariggiano I, Di Maio D, Concilio C, Taglialatela V, Fimiani F, Cesaro A, Cirillo PL, Calabro P. Improving adherence to Ticagrelor in patients after acute coronary syndrome: results from the progress trial. Curr Vasc Pharmacol. 2020;18:294-301.

29. Schwartz GG, Steg PG, Szarek M, Bhatt DL, Bittner VA, Diaz R, Edelberg JM, Goodman SG, Hanotin C, Harrington RA, Jukema JW, Lecorps G, Mahaffey KW, Moryusef A, Pordy R, Quintero K, Roe MT, Sasiela WJ, Tamby JF, Tricoci P, White HD, Zeiher AM, Committees OO, Investigators. Alirocumab and cardiovascular outcomes after acute coronary syndrome. New Engl J Med. 2018;379:2097-107.

30. Gragnano F, Fimiani F, Di Maio M, Cesaro A, Limongelli G, Cattano D, Calabro P. Impact of lipoprotein(a) levels on recurrent cardiovascular events in patients with premature coronary artery disease. Intern Emerg Med. 2019;14:621-5.

31. Cesaro A, Schiavo A, Moscarella E, Coletta S, Conte M, Gragnano F, Fimiani F, Monda E, Caiazza M, Limongelli G, D'Erasmo L, Riccio C, Arca M, Calabro P. Lipoprotein(a): a genetic marker for cardiovascular disease and target for emerging therapies. J Cardiovasc Med. 2021;22:151-61.

\section{Publisher's Note}

Springer Nature remains neutral with regard to jurisdictional claims in published maps and institutional affiliations.

Ready to submit your research? Choose BMC and benefit from

- fast, convenient online submission

- thorough peer review by experienced researchers in your field

- rapid publication on acceptance

- support for research data, including large and complex data types

- gold Open Access which fosters wider collaboration and increased citations

- maximum visibility for your research: over $100 \mathrm{M}$ website views per year

At BMC, research is always in progress.

Learn more biomedcentral.com/submissions 